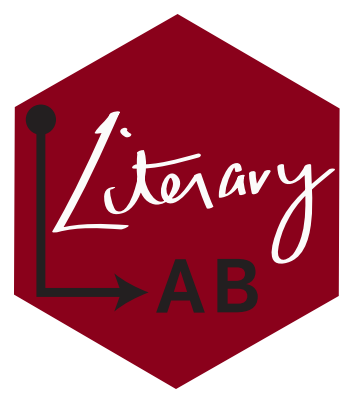

Pamphlet

$\rightarrow$ December 2013

\title{
Literary Lab
}

"Operationalizing": or, the function of measurement in modern literary theory

Franco Moretti 
Pamphlets of the Stanford Literary Lab 


\section{“Operationalizing":}

\section{or, the function of measurement in modern literary theory ${ }^{1}$}

An uncommonly ungainly gerund, "operationalizing" is nevertheless the hero of the pages that follow, because it refers to a process which is absolutely central to the new field of computational criticism, or, as it has come to be called, of the digital humanities. Though the word is often used merely as a complicated synonym for "realizing" or "implementing" - the Merriam-Webster online, for instance, mentions "operationalizing a program", and adds a quote on "operationalizing the artistic vision of the organization"-the origin of the term was different, and much more precise; and for once origin is right, this is one of those rare cases when a word has an actual birth date: 1927, when P.W. Bridgman devoted the opening of his Logic of modern physics to "the operational point of view". Here are the key passages:

We may illustrate [the meaning of the term] by considering the concept of length: what do we mean by the length of an object? [...] To find the length of an object we have to perform certain physical operations. The concept of length is therefore fixed when the operations by which length is fixed are fixed: that is, the concept of length involves as much and nothing more than the set of operations by which length is determined. In general, we mean by any concept nothing more than a set of operations; the concept is synonymous with the corresponding set of operations [...] the proper definition of a concept is not in terms of its properties but in terms of actual operations. ${ }^{2}$

The concept of length, the concept is synonymous, the concept is nothing more than, the proper definition of a concept ... Forget programs and visions; the operational approach refers specifically to concepts, and in a very specific way: it describes the process whereby concepts are transformed into a series of operations-which, in their turn, allow to measure all sorts of objects. Operationalizing means building a bridge from concepts to measurement, and then to the world. In our case: from the concepts of literary theory, through some form of quantification, to literary texts.

1 This pamphlet has taken shape in a back-and-forth between my two favorite workplaces: the Wissenschaftskolleg in Berlin, and the Literary Lab at Stanford. To the people who make them what they are, and to Ryan Heuser in particular, my profound gratitude.

2 P.W. Bridgman, The logic of modern physics, Macmillan, NY, 1927, pp. 5-6. 


\section{Operationalizing character-space}

Taking a concept, and transforming it into a series of operations. Concretely, how does one do that? My first example concerns one of the most important contributions to literary theory of the past twenty or thirty years: the concept of "character-space", coined by Alex Woloch in The One vs. The Many. Here is the initial cluster of definitions:

the amount of narrative space allocated to a particular character [...] the space of the character within the narrative structure [...] the space that he or she occupies within the narrative totality [...] the narrative's continual apportioning of attention to different characters who jostle for limited space within the narrative totality... ${ }^{3}$

So, what are the "operations we have to perform", to find out the amount of narrative space allotted to Molly Bloom, or lago, or any other character? Graham Sack has answered by taking the path of so-called "instrumental variables": features that we use as proxies for the variables we are interested in, when the latter are-for whatever reason-impossible to measure. Working on nineteenth-century novels, Sack measured how often they mentioned the names of the various characters; though name frequency is not the same as characterspace, they are clearly correlated-and Sack's proxy worked in fact quite well for Austen, Dickens, and many other writers. ${ }^{4}$

I took a different approach, which assumed that character-space could actually be measured directly. Texts are made of words, lines, pages, and one can definitely measure those. But there are complications. Take this sentence from the first chapter of Pride and Prejudice:

Mr. Bennet was so odd a mixture of quick parts, sarcastic humour, reserve, and caprice, that the experience of three-and-twenty years had been insufficient to make his wife understand his character.

Where does Mr. Bennet's "space" end and Mrs. Bennet's begin, in this sentence? Sack's proxy would score one for Mr. Bennet and zero for his wife, and it's reasonable, in so far as naming a character is always a way of foregrounding it; on the other hand, a larger portion of the sentence refers to Mrs. Bennet's perception, and all that is completely lost. Plays are easier in this respect; as there are no ambiguities in how words are distributed among the various speakers, character-space turns smoothly into "word-space"- "the number of words allocated to a particular character"-and, by counting the words each character utters, we can determine how much textual space it occupies. In Racine's Phèdre, for instance, Phèdre utters $29 \%$ of words, Hyppolite 21 , Thésée 14 , and so on all the way to the $0 \%$ of the guards who silently obey Thésée's orders in the final act of the play (Figure 1).

3 Alex Woloch, The One vs. The Many. Minor Characters and the Space of the Protagonist in the Novel, Princeton UP, 2003, pp. 13-4.

4 Graham Alexander Sack, "Simulating Plot: Towards a Generative Model of Narrative Structure”, 2011, Papers from the AAAI Fall Symposium (FS-11-03). 


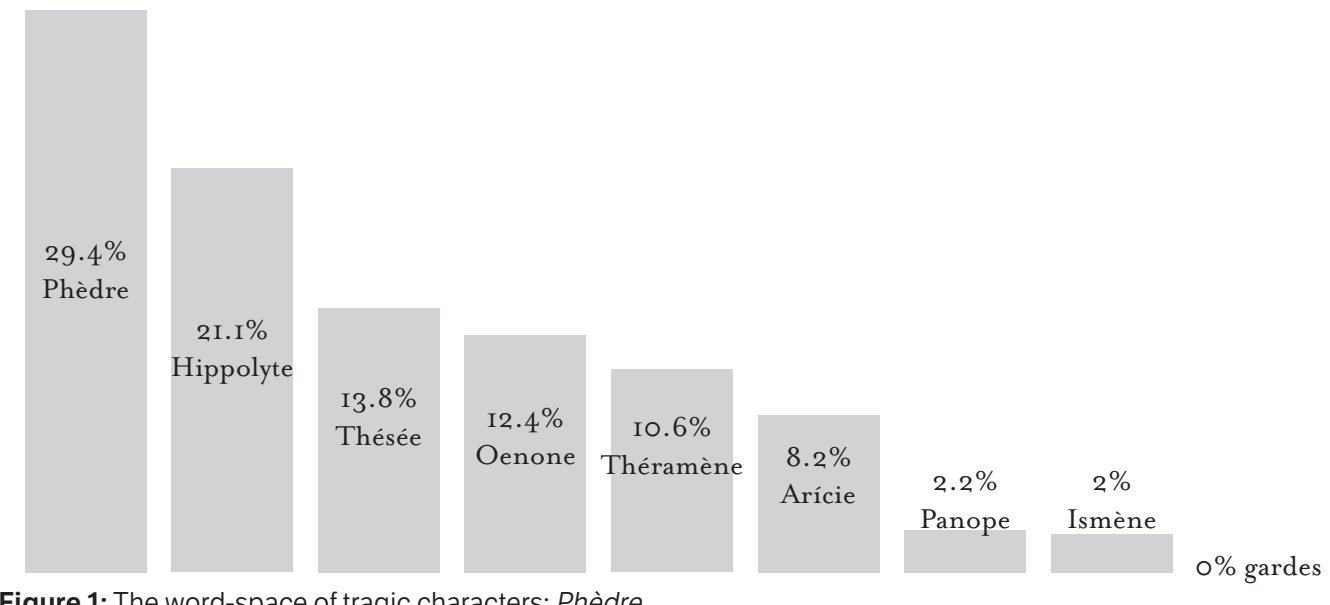

Figure 1: The word-space of tragic characters: Phèdre.

It is a simple, plausible way of measuring character-space. But it's not the only way. Network theory, for instance, has taught us to measure the links a character has with the rest of the "character-system" (another of Woloch's concepts), and the "weight" of those links (the number of words exchanged between any two characters), as well as their "direction" (who is speaking to whom) - and, with each new measurement, new aspects of Phèdre become visible. If the histogram had already shown that Phèdre speaks more than the other characters in the play, the network adds that the largest part of her word-space is taken, not by exchanges with her husband Thésée or would-be lover Hyppolite, but with her "confidante" Oenone: a result which is not inevitable, and is in fact quite significant for neo-classical poetics (Figure 2). The network also shows how "an-isotropic" word-spaces tend to be: in most cases, language doesn't flow equally in every direction: Phèdre speaks to Oenone much more than the other way around; same between Phèdre and Hyppolite, Hyppolite and Aricie,

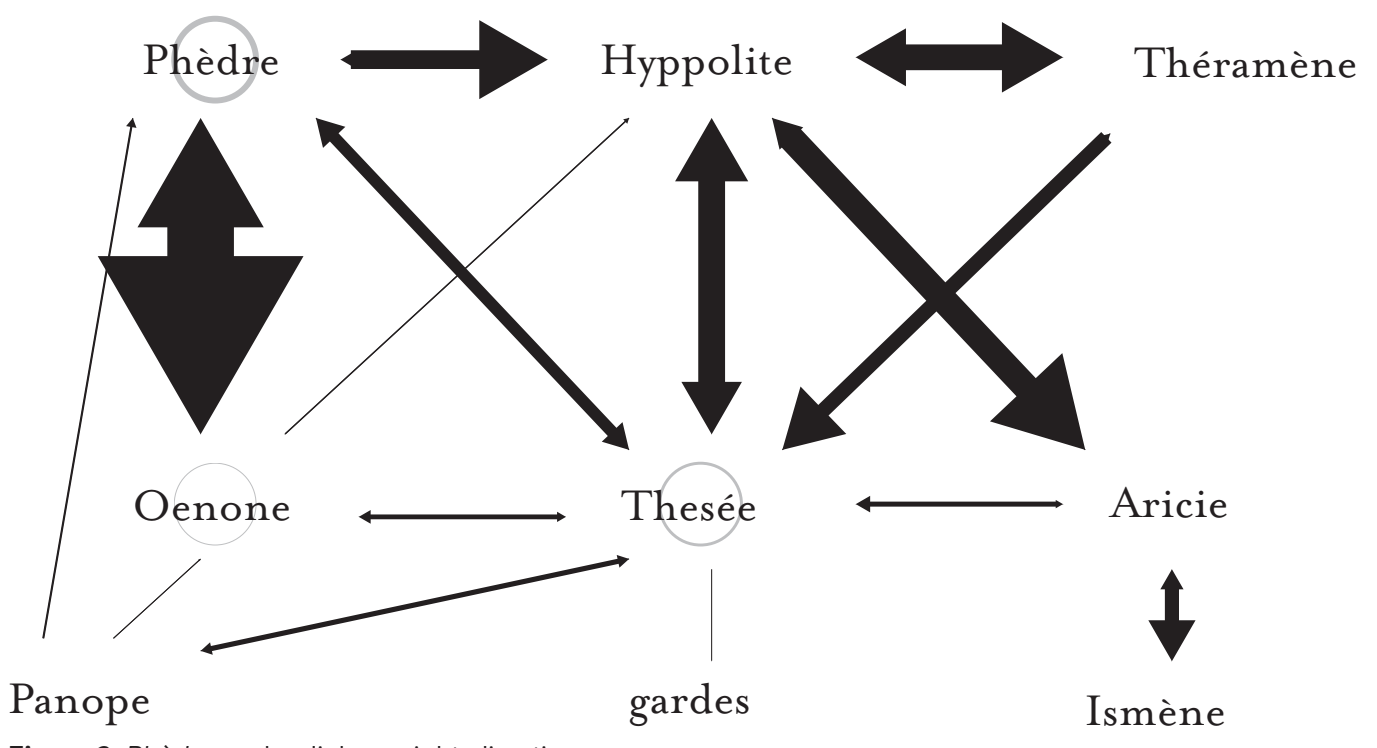

Figure 2: Phèdre: nodes, links, weight, direction. 
Aricie and Ismène. Or again; if one thinks of Phèdre's most famous narrative passage — the "récit de Théramène"- the network makes immediately visible how decentered that speech act is from much of the play, and especially from Phèdre herself. And I could continue to use this diagram to analyze other aspects of the play; but l'd rather take a step back and ask: so, what has operationalizing actually done? Let's assume that deriving quantitative data from Woloch's concept has added something to our knowledge of Phèdre: what exactly is that "something"?

\section{The function of measurement}

Fifty years ago, Thomas Kuhn wrote an essay which presents measurement-that is to say, the act of "producing actual numbers": like those that are behind Figures 1-2 -as something which, far from being obvious, is in fact badly in need of theoretical and practical justification. Though many believe that measurement is useful because "numerical data are likely to be productive of new generalizations", for Kuhn this hope is completely groundless: "numbers gathered without some knowledge of the regularity to be expected", he observes, in a before-the-fact critique of what today would be called "data-driven" research, "almost certainly remain just numbers"; no new "laws of nature" will ever be "discovered simply by inspecting the results of measurements". Measurement does not lead from the world, via quantification, to the constructions of theories; if anything, it leads back from theories, through data, to the empirical world. "The new order provided by a new theory is always overwhelmingly a potential order", writes Kuhn; potential, because the "laws" of the theory "have so few quantitative points of contact with nature", that they are, as it were, floating above the world of empirical facts. Measurement rectifies this weakness; it provides "an investigation of those contact points", thus strengthening the connections between laws and reality, and transforming that "overwhelmingly potential order" into an "actual" one. Measurement anchors theories to the world they describe. ${ }^{5}$

Now, I don't know whether scientific theories have really so few points of contact with nature; for literary theories, though, this is certainly the case, and is also why measurement matters so much: it makes some concepts "actual" in the strong sense of the word; it takes characterspace, and proves that there is something in the real world (the real world of fictions) that corresponds to it. Not all concepts are born equal, some are better than others, and operationalization, though not the only test of a theory, is an important one. It shows that, by following a series of steps, you can turn abstractions into a clear and, hopefully, unexpected elaboration of reality. Like the diagram in Figure 2: a pair of concepts, a few simple rules, and a new image of Phèdre emerges. But, again: new, how?

5 Thomas Kuhn, "The function of measurement in modern physical science", 1961, in The Essential Tension. Selected Studies in Scientific Tradition and Change, Chicago UP, 1977, pp. 180, 183, 197-8, 188 (italics in the original). 


\section{Concept against concept}

First of all, it's new because it's precise. Phèdre is allocated $29 \%$ of the word-space, not 25 , or 39. Historical novels have recently become more frequent in high literature, observed Perry Anderson a few years ago; and, in a workshop at the Literary Lab, James English showed how that "more frequent" can be translated into "between 40 and $50 \%$ of novels nominated for literary prizes"; and "recently" into: "beginning in the 1980s".

Precision is always good. Or is it? "It is ridiculous to attempt a precise measurement of the dimensions of a natural being", wrote Alexandre Koyré, in an essay with the wonderful title "From the world of the 'more-or-less' to the universe of precision":

reality, the reality of everyday life, within which we exist and live, is not mathematical [...] there is everywhere a margin of imprecision, of 'play', of 'more or less', of 'just about' [...] A little more, a little less ... what importance can that have? In most cases, undoubtedly, none whatsoever. ${ }^{6}$

Establishing that Phèdre speaks $29 \%$ of the words in the play instead of 25 or 39 -what importance does this have? We knew she spoke "more" than the other characters; does the "actual number" produced by measurement modify that? No. It adds detail, but it doesn't change what we already knew. And if this is all measurement can do, then its role within literary study will only be a limited and ancillary one; making existing knowledge somewhat better, but not really different.

Disappointing. Yet, fortunately, this is not all that measurement can do. When one looks at Figure 1, that Phèdre is the protagonist of the play seems to go without saying. When we measure the links in the network of Figure 2, though, Thésée is clearly more central than her. Two distinct criteria for protagonism emerge: the volume of words, and the number of interactions. And it's not that one is right and the other is wrong; rather, they capture different features of dramatic networks: the number of links tells us how connected a character is (and is often correlated with proximity to power, like here Thésée); the number of words tells us how much meaning the character brings into the play (and is often correlated with a discord with power, like here Phèdre). There are cases in which the two criteria of centrality coincide, most spectacularly in Macbeth (Figure 3), where Macbeth dominates both the word-space and the network of the play; but the disagreement between them, or a difference which is too slight to be significant, are actually much more frequent: in Othello (Figure 4), for instance, lago has a larger word-space than Othello, but not by much; same with Carlos and Posa in Don Carlos (Figure 5), or several characters in Ghosts (Figure 6); or, most striking of all, in Antigone; the paradigm of tragic conflict for Hegel and so many others, yet one in which the heroine speaks far fewer words, and has significantly fewer connections to the rest of the character-system than either Creon or the Chorus (Figures 7-8).

6 Alexandre Koyré, “Du monde de l' 'à-peu-près' à l'univers de la précision", 1948, now in Études d'histoire de la pensée philosophique, Gallimard, Paris 1961, pp. 340, 348. 


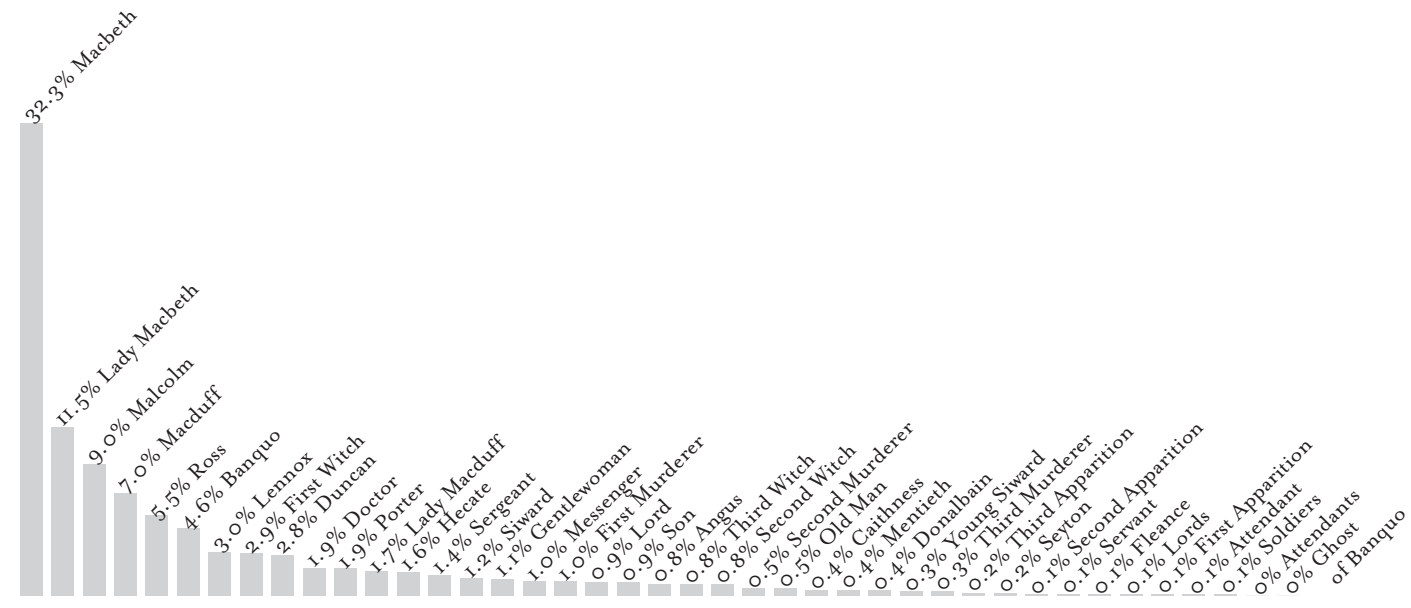

Figure 3: The word-space of tragic characters: Macbeth.

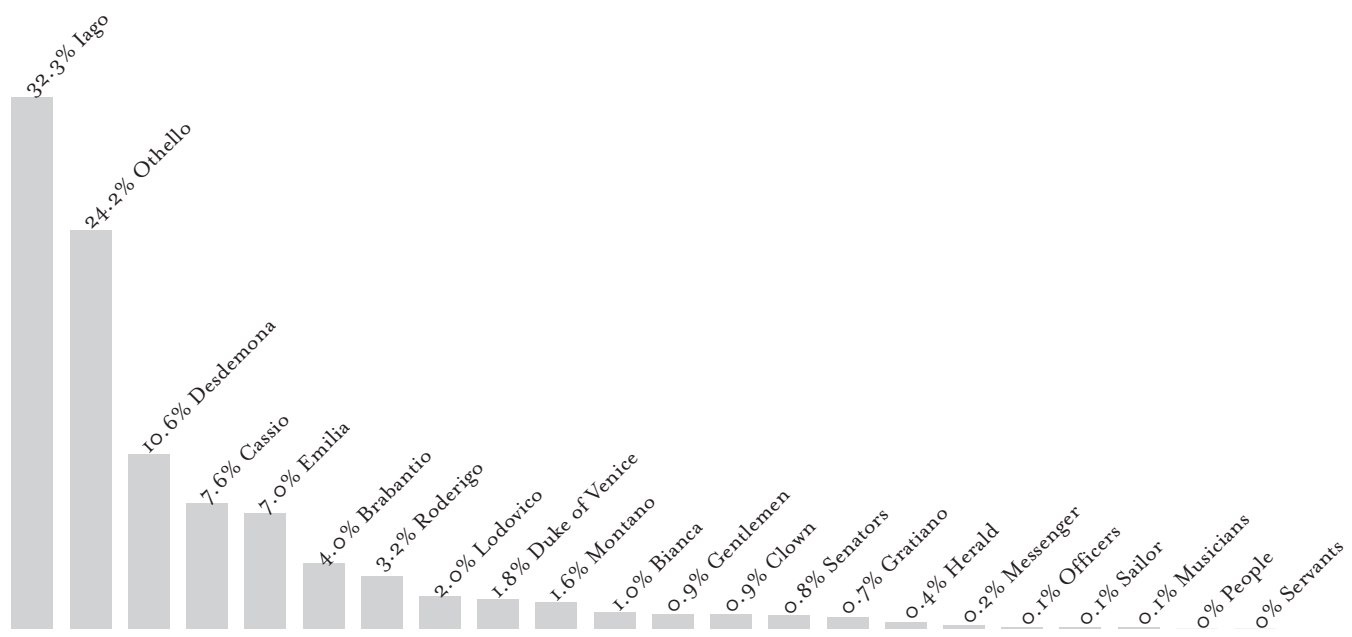

Figure 4: The word-space of tragic characters: Othello.

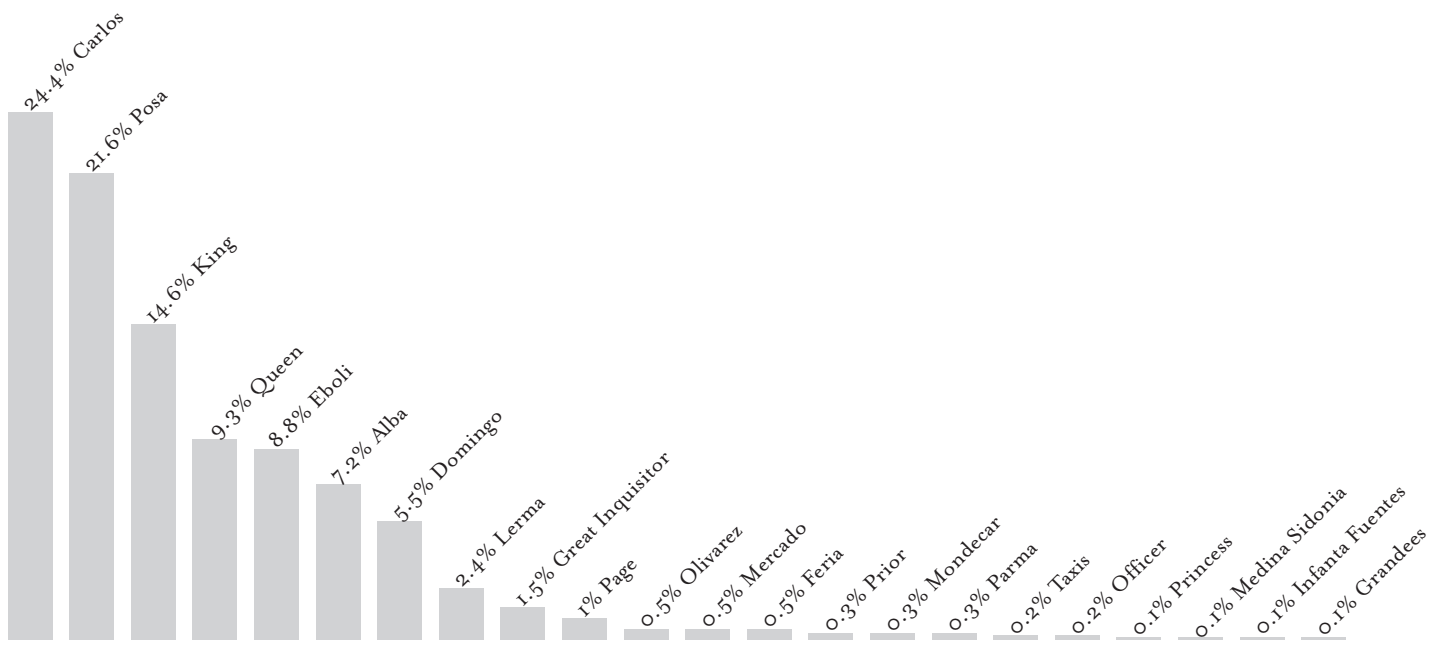

Figure 5: The word-space of tragic characters: Don Carlos. 

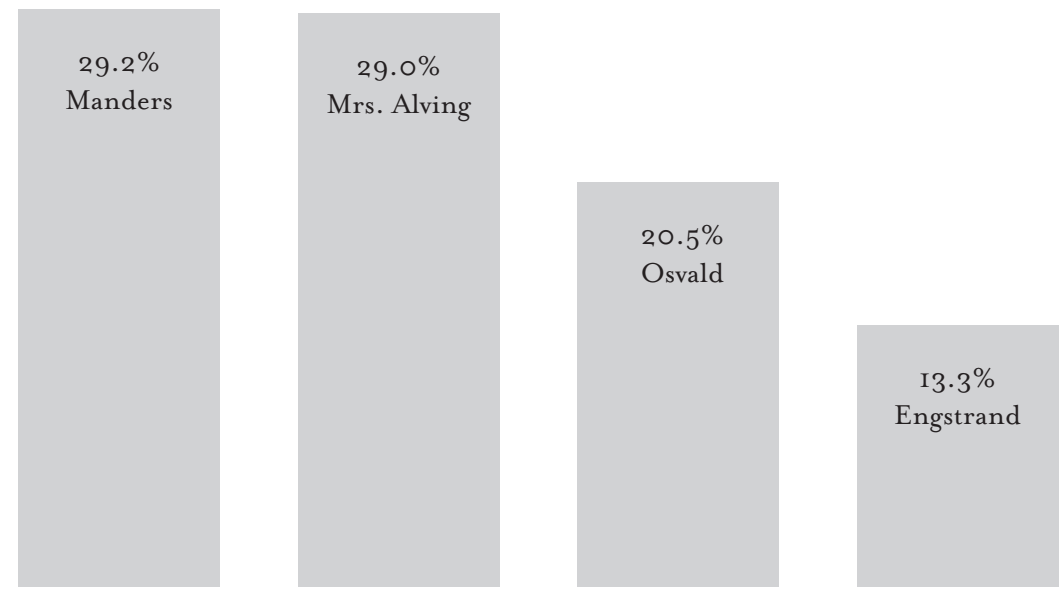

$7.8 \%$

Regine

Figure 6: The word-space of tragic characters: Ghosts.
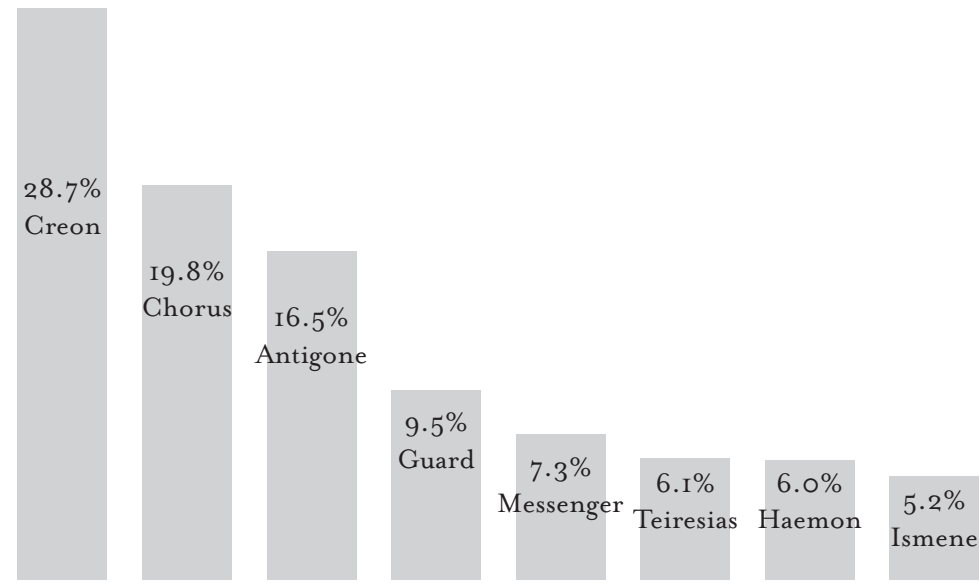

$0.6 \%$
Eurydice

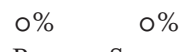

Figure 7: The word-space of tragic characters: Antigone.

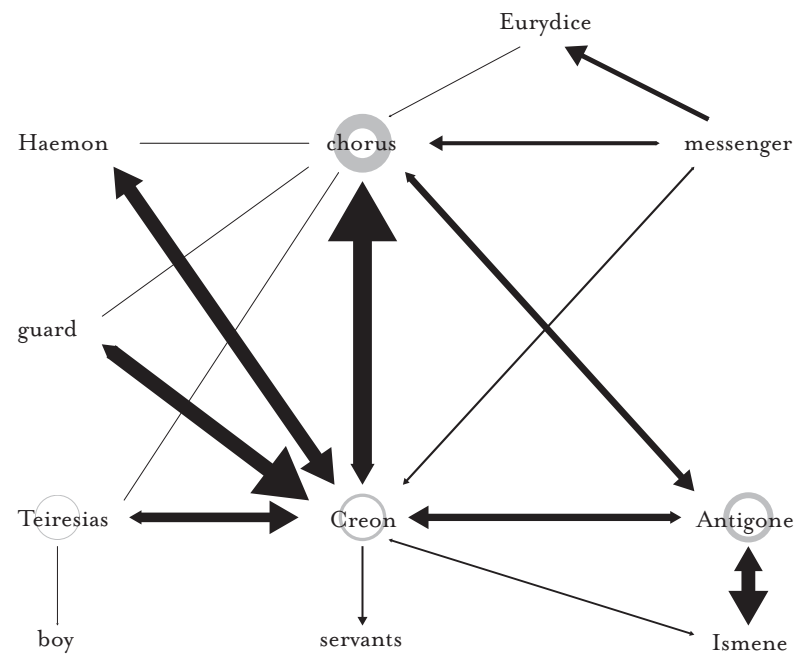

Figure 8: Antigone: nodes, links, weight, direction. 
What can measurement do for literary study? In this case, it shows that the "protagonist", far from being a fundamental reality of dramatic construction, is only a special instance of the more general category of "centrality". Centrality exists always; Macbeth, is a limit case. Concept against concept: the measurement of character-space undermines the older notion, replacing it with the idea of a conflict arising near the center of the network. And something very similar happens at the opposite end of the spectrum, among the "minor characters" that populate the periphery of dramatic systems. In this network of Hamlet for instance (Figure 9), reproduced from my earlier pamphlet on “Network Theory, Plot Analysis”, are Reynaldo, the Priest, the second grave-digger, all the attendants and messengers who hang to the plot by a single thread-and that, in Shakespeare, add up to about half of the charactersystem-are they all "minor characters" in the same sense as Gertrude, Polonius, or even Rosencrantz? In his book (116-9), Woloch evokes the idea of "minor minor characters", and Figure 9 radicalizes his insight: to be connected to a network by a single link, or by four or five, is not a matter of emphasis ("minor", and "minor minor"), but of function: "obedience" (or, much more rarely, dis-obedience) for single-link characters; and "mediation" for those who, because of their various connections, are almost always linked to more than one network region.?

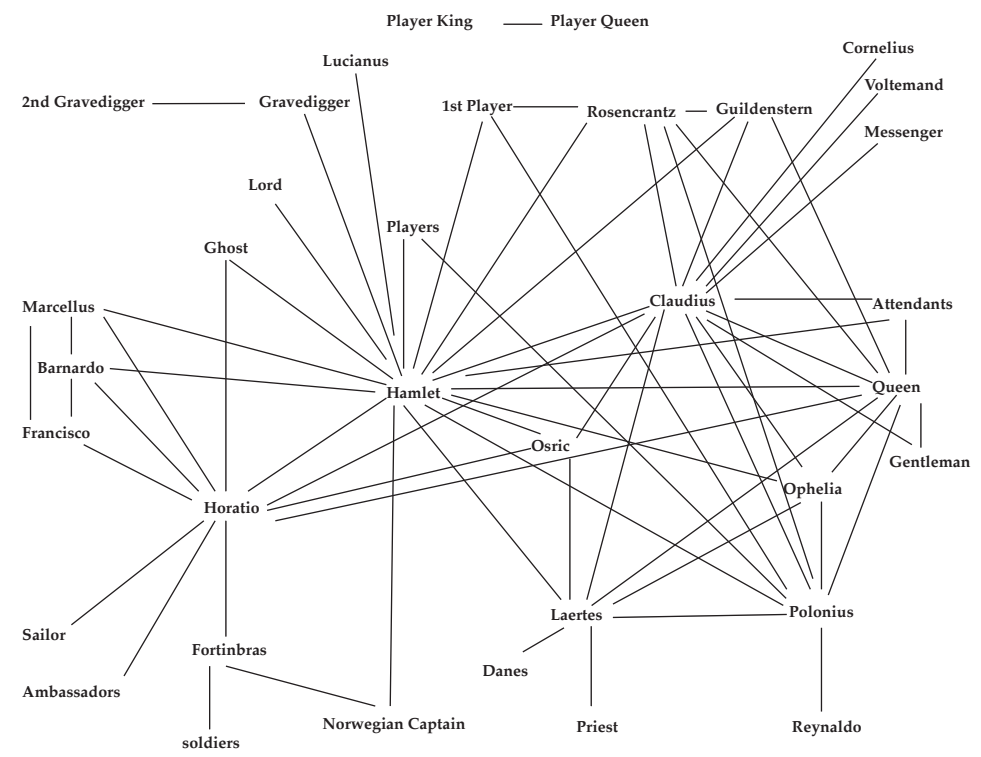

Figure 9: Hamlet: nodes and links. This figure includes neither weight nor direction of the links, as they are not necessary for the argument developed in the text. In general, however, the weight of peripheral links is well below $1 \%$-in most cases, close to $0.1 \%$ of the total word space.

Needless to say, the trio of "conflict", "mediation", and "obedience" is a hypothesis, just as the older pair of protagonist and minor character. But the new categories have the advantage

7 Almost always: so-called "cliques" possess several local connections, while remaining substantially disconnected from the body of the play (more or less like the group formed by Bernardo, Francisco and Marcellus in Figure 9). In the relatively small character-systems of drama, cliques tend to be rare; in novels, they are much more significant. 
of referring to specific aspects of the plot, and of the social world that is being represented; plus, they agree much better with quantitative evidence. Koyré again:

a utensil [...] amplifies and strengthens the action of our body, of our sense organs: it is something that belongs to the world of common sense-and that will never allow us to go beyond that world. Such, by contrast, is precisely the function of the instrument: which is not an amplification of our senses but, in the strongest and most literal sense of the term, is an incarnation of the spirit, a materialization of thought [...] the conscious realization of a theory. [...] It is for purely theoretical reasons, in order to reach what does not fall under the domain of our senses, to see what no one had ever seen before, that Galileo constructed his instruments, the telescope and then the microscope. $(352,357)$

The protagonist is a utensil; character-space, is an instrument. The protagonist is a utensil because it belongs to the world of readerly common sense, and doesn't go beyond it. Character-space is an instrument, because it's the realization of a theory that wants to understand something "that does not fall under the domain of our senses": instead of individual characters, the relations among characters. That's why, in the end, its operationalization produced more than the refinement of already-existing knowledge: not the protagonist, improved, but an altogether new set of categories. Measurement as a challenge to literary theory, one could say, echoing a famous essay by Hans Robert Jauss. This is not what I expected from the encounter of computation and criticism; I assumed, like so many others, that the new approach would change the history, rather than the theory of literature; and, ultimately, that may still be the case. But as the logic of research has brought us face to face with conceptual issues, they should openly become the task of the day, countering the pervasive clichés on the simple-minded positivism of digital humanities. Computation has theoretical consequences-possibly, more than any other field of literary study. The time has come, to make them explicit.

\section{Operationalizing tragic collision}

I have spent so much time on character-space because the concept is clear, fruitful-and easy to operationalize; not that Woloch had this in mind as he was writing his book, but he was writing from within a paradigm—broadly speaking, structuralism—where quantification, though seldom activated, was in principle a perfectly acceptable option. The trouble is, most literary concepts are emphatically not designed to be quantified; and the question then arises of what to do with them.

Bridgman, in his book, had offered an answer. In the light of the operational point of view, he had written, "thinking becomes simpler": "old generalizations [...] become incapable of use", and "many of the speculations of the early natural philosophers become simply unreadable" (31-2). I disagree with this nonchalant dismissal, and, in the second part of this pamphlet, will do exactly the opposite of what Bridgman recommends: I will take one of the peaks of 
speculative aesthetics - Hegel's conception of tragic conflict—and try to chart a path from this "old generalization" to the world of empirical data. ${ }^{8}$

To begin with, a few definitions:

What is properly dramatic is the speech of individuals in the conflict of their interests and the discord of their characters and passions.

The completely dramatic form is the dialogue. For in it alone can the individual agents express face to face their character and aim, both their personal character and the substance of their animating 'pathos'; in it alone can they come into conflict and so actually move the action forwards.

What drives them to act is precisely an ethically justified 'pathos' which they assert against one another with the eloquence of their 'pathos' not in sentimental and personal rhetoric or in the sophistries of passion, but in solid and cultivated objective language. ${ }^{9}$

There are some differences among these passages, but they all converge on the same two main points. The first is conflict: Kampf: "battle", "fight". But for Hegel tragic Kampf is not (just) destruction; it is also a productive process that gives rise to "speech", "dialogue”, "ethically justified "pathos", "cultivated objective language". With them, a new element enters the discussion. Character-space could be directly translated into other spatial configurations, such as bars, or networks; "ethically justified "pathos"” and "cultivated objective language", however, entail meaning — and, in order to operationalize that, additional steps become necessary. In this case, I took ten Greek tragedies in which a central collision was particularly clear, ${ }^{10}$ and proceeded to establish the meanings — or at least, the words — most distinctive of their main antagonists.11

As the results were similar throughout the corpus, I focused on Hegel's master example of Antigone: where the "chief conflict", reads the famous formulation of the Aesthetics, occurs "between the state, i.e. ethical life in its spiritual universality, and the family, i.e. natural

8 As it will become clear, I assume that Hegel's theory can be operationalized. This leaves open two further questions. First: and if it couldn't? Would the theory lose all its value, and deserve to be forgotten? The second question is almost opposite in nature: if applied too loosely and widely, wouldn't operationalizing lose the strict falsifying potential that had made it so valuable in the first place? In principle (though a full motivation will have to wait for another occasion), my answers would be, No to the first question, and Yes to the second. On how uncritical operationalizations have ended up "legitimating (...) 'metaphysical' concepts instead of replacing them" in the fields of both economics and psychology, see Wade Hands, "On operationalisms and economics", Journal of Economic Issues, 2004.

9 Georg Wilhelm Friedrich Hegel, Aesthetics, Oxford UP, 1975, pp. 1171, 1172-3, 1214-5.

10 Five tragedies by Aeschylus, and five by Sophocles: Agamemnon, Libation Bearers, Eumenides, Suppliant Maidens, Prometheus, Antigone, Philoctetes, Oedipus at Colonus, Ajax, Electra.

11 To do this, the Literary Lab follows an approach (which we call Most Distinctive Words) in several steps. First, we establish how often a word occurs in the corpus, and hence how often a specific character is expected to use it given the amount of words at its disposal; then we count how often the character actually utters the word, and calculate the ratio between actual and expected frequency; the higher the ratio, the greater the deviation from the average, and the more typical the word is of that character. 
ethical life" (1213). And here are the nouns that emerged as most distinctive of, respectively, Antigone and Creon:

Antigone: brother mother marriage home friend love honor tomb hades misery law

Creon: ruin evil fear woman men god money

Antigone's terms clearly incline towards family and mourning; Creon's are more abstract and threatening. But they are, more or less, what one would have expected. Then, verbs:

Antigone: die leave go share rest

Creon: let take stand shall find tell make may know be

Here, Creon's peremptory tone produced a modestly interesting finding vis-à-vis Hegel: if Antigone's results again evoked the "natural ethical life" of family piety, Creon's language was not that of the State as "spiritual universality"-it was the State as mere power to coerce: let take stand find tell make ... Imperative, often callous: "Take yourself away"; "If you do not find the author..."; "Tell me, did you know of the proclamation"; "Tell me, do you admit being a party to the burial"; "Let there be no delay, take her"; "Let her keep invoking the Zeus of kindred"; "Let him act so, let him go". Still, the finding was indeed modest; many had already observed that Hegel had exaggerated the spiritual significance of Creon; our evidence corroborated this critique, and corroboration is not nothing, but is also not much. Antigone and Creon, the tragic conflict, I was hoping for more than this.

\section{Operationalizing tragic collision. Second attempt}

Then I realized that the words I was looking at were indeed distinctive of Antigone and Creon, but they were so at the scale of the play as a whole; they included what each of them said to the Chorus, to Ismene, the guard, Haemon, Teireisias ... The words were distinctive, yes, but not of their conflict. And instead, on this point, Hegel had been extremely clear:

in [dialogue] alone can the individual agents express face to face their character and aim [...] come into conflict and so actually move the action forwards. (1172-3)

an ethically justified 'pathos' which they assert against one another with the eloquence of their 'pathos' [...] in solid and cultivated objective language. (1214-5)

"Express face to face", "assert against one another"; in both cases, the German is the same: gegeneinander, an adverb that inscribes conflict (gegen, against) in the very body of the word. In establishing Antigone's and Creon's most distinctive words, I had completely overlooked this conjunction of self-expression with the gegeneinander; that's why the results 
had been so predictable. On my second attempt, I extracted only the passages when Antigone and Creon speak to each other, generated a new list of most distinctive words, and -

Antigone: gods son power corpse

Creon: death woman evil

Possibly the opposition was sharper than before; certainly it was much more limited. In part this was so because the new pool of words was smaller than the old one; but the truth is that, when Antigone and Creon are face to face, their language becomes, not more substantial and objective, as Hegel would have it, but less so:

Creon: You alone among the Cadmeans see this.

Antigone: They see it too; but they curb their tongues to please you.

Creon: Are you not ashamed of thinking differently from them?

Antigone: There is no shame in showing regard for those of one's own stock.

Creon: Was not he who died on the other side also your brother?

Antigone: My brother with the same mother and the same father. (508-13)12

Tragedy is "a real murder via words", wrote Hölderlin in his annotations to Antigone, and this line-by-line attack and defense-known as stichomythia, or verse-speech-is probably what he had in mind; a rhetoric that makes tragic opposition at once extremely clear, and extremely narrow. Clear: You alone see this / They see it too. Are you not ashamed / There is no shame. But narrow: because the conflict between the speakers is expressed by reiterating-negating the same terms (see, shame, brother), rather than evoking the large value systems (brother-home-love-tomb-law; let-take-stand-find-tell) that had been plainly visible at the scale of the play as a whole. There, the conflict between Antigone and Creon had found expression in their very different "objective languages"; in stichomythia, it has been drastically contracted to the opposite sides of a lowest common denominator. The dramatic effect is heightened-but at the expense of semantics. It is not in these lines that we can find the meaning of Antigone.

It is not in these lines ... Yet, the operationalization of Hegel's theory of tragic collision has led us precisely to these lines. Another mistake? No; this time, god forgive me, the mistake was Hegel's - it lay in the connection he posited between face-to-face confrontations and the "gebildete Objectivität" of tragic language. Separately, both notions are true; it is their conjunction that isn't. Face-to-face confrontations do occur in tragedy, and find a memorable expression in the rhetoric of stichomythia; but stychomithia does not convey the "ethically justified pathos" that Hegel had in mind. This pathos also exists of course, and constitutes the very core of Greek tragedy; but it is not dependent on the gegeneinander of face-to-face encounters; it emerges much more clearly in Antigone's exchanges with her sister Ismene, or in her long speech to the Chorus (and, through the Chorus, to the audience: "Look at me, citizens of my fatherland..."), than in her confrontation with Creon. The moment of crisis is

12 All quotes from Antigone are from the Loeb edition, Harvard UP, 1995. 
not a moment of truth: it exerts too much pressure on the acting subjects for Hegel's "cultivated objectivity" to shine through. And a whole new relationship between conflict and values becomes necessary as a result. ${ }^{13}$

Did we need operationalizing, to reach this conclusion? This is not for me to say. What I will say is that the leap from measurement to reconceptualization, that has characterized both parts of this essay (though in Hegel's case the new categories have yet to emerge), demonstrates how the unprecedented empirical power of digital tools and archives offers a unique chance to rethink the categories of literary study. Digital humanities may not yet have changed the territory of the literary historian, or the reading of individual texts; but operationalizing has certainly changed, and radicalized, our relationship to concepts: it has raised our expectations, by turning concepts into magic spells that can call into being a whole world of empirical data; and it has sharpened our skepticism, because, if the data revolt against their creator, then the concept is really in trouble. A theory-driven, data-rich research program has become imaginable, bent on testing, and, when needed, falsifying the received knowledge of literary study. Of this enterprise, operationalizing, will be the central ingredient.

13 A parallel line of argument would stress the unique role played in stichomythia by Greek particles. Half conjunctions, half sentence adverbs for mood and attitude-men, ge, kai, de, gar, alla, oun, te, kai ge, kai men: surely, yes but, at least, in fact, truly, on the other hand, indeed, of course, even...-particles are very frequent in stichomythia (though they are often lost in translation), because they are great at expressing conflict. But they express it in their own unique way: Färbung, "coloring", is the favorite cognitive metaphor of the critical literature. Particles bring about "a loss of definiteness (compensated) by increased subtlety", states their classic study: "less body, and more bouquet”. It's hard to imagine a less Hegelian statement-and that's precisely the problem: the style of face-toface confrontations, by making a large use of particles and of their peculiar rhetoric, results in the opposite of the "cultivated objective language" that Hegel had identified with tragic collision. See Adolf Gross, Die Stichomythie in der griechischen Tragödie und Komödie, ihre Anwendung und ihr Ursprung, Leipzig, 1905; John Leonard Hancock, Studies in Stichomythia, Chicago UP 1917; J. D. Denniston, The Greek Particles (1935), second edition, revised by K.J. Dover, Duckworth, London 1950, p. xxxvii. 